\title{
High dietary diversity is associated with child obesity in Iranian school children: An evaluation of dietary diversity score.
}

\author{
Hooshmand S*, Marhamati F \\ Den Haag, The Hauge, Netherlands
}

\begin{abstract}
Objective: The prevalence of overweight and obesity in Iranian children has increased considerably in the last decades. Obesity in children is a major concern. Higher variety score of diet may cause obesity and overweight among urban schoolchildren. The objective of this study was to measure dietary diversity score and obesity in child from Iran.

Methods: The present study examined Dietary Diversity Score(DDS) and weight status by calculating Body Mass Index (BMI) and the World Health Organization's (WHO) anthropometric indices of weight-for-age (WA) and weight-for-height. A cross sectional study was performed on 2500 Iranian school children 1176 girls and 1324 boys aged 6-9 years, attending primary schools residing in urban area from low and middle-income categories. Dietary diversity scores were assessed based on frequency of consumption of individual food items categorized into 11 individual food groups.

Results: Overweight children showed the highest mean score for cereals $(F=2.209, P=0.005)$, vegetables $(F=5.234, P=0.001)$, non-vegetarian foods $(F=12.3920, P=0.000)$, mixed dishes $(\mathrm{F}=9.899, \mathrm{P}=\mathbf{0 . 0 0 0})$, beverages $(\mathrm{F}=9.654, \mathrm{P}=\mathbf{0 . 0 0 0})$, sweets and sugar $(\mathrm{F}=5.122, \mathrm{P}=0.002)$ and fats $(F=10.263, P=0.000)$. Mean scores for vegetables, sweets, beverages and fat consumption increased with increasing weight. High scores for pulses and legumes consumption was observed in obese children. Scores for vegetable consumption were higher among overweight children.
\end{abstract}

Conclusion: Overweight and obese school children had high diversity scores in their diet.

Keywords: Dietary diversity, Child obesity, Anthropometry

\section{Introduction}

Obesity is a major public health concern. There is substantial body of evidence that the prevalence of overweight has been significantly increased among children in recent years [1]. The study published by World Health Organization (WHO) indicated that in the number of obese children rose from 11 million in 1975 to 124 million in 2016 a tenfold increase. An additional 216 million children were overweight. (WHO, 2017) According to world health organization 2014, the vast majority of overweight or obese children live in developing countries were $30 \%$ higher than that of developed countries. By the same trends it will increase to 70 million by 2025 as per WHO in 2014. Measuring Body Mass Index (BMI) has been recommended by many authors for evaluation of childhood obesity [2]. Overweight or obese children show high risks for hypertension, diabetes mellitus type 2, metabolic disorder, and mental disorders [3]. In National Health and Nutrition Examination Survey (NHANES), the prevalence of overweight among children aged 6-11 years was increased by about $11 \%$ from 1970-1974 till 1999-2000 in the USA [4]. A study by Kelishadi et al. showed in Iran, prevalence of overweight and obesity in children aged 6-18 years was $10.1 \%$ and $4.79 \%$ according to national cut-offs [5]. The epidemic of child obesity in Iran caused by the rapid nutrition and physical activity transition. Energy-dense and often poor-quality foods are more widely available, and the typical lifestyle of many children is characterized by low levels of physical activity [6]. Children need a variety of foods to meet their body requirements for essential nutrients, and the value of a diverse diet has long been recognized [7]. Because of the perceived importance of dietary diversity for health and nutrition, indicators of dietary diversity have become increasingly popular in recent years [8]. They are relatively simple to measure and they are thought to reflect nutrient adequacy, i.e., individuals consuming more diverse diets are thought to be more likely to meet their nutrient needs [9].

Dietary variety instruments (often called dietary diversity scores or food variety scores) have recently become the preferred method for studying dietary adequacy in developing countries. These scores consider the number of different food items or food groups contributing to the diet in a given time period. They are useful because they are correlated with nutrient intakes as well as various anthropometric measures in children; measurements are simple to collect and easily adapted to diet in various settings. They have been used to study diet in both early childhood and adulthood [10]. 
Although higher variety score of a diet is associated with increased fiber intake, vitamin $\mathrm{C}$ and calcium, which are inversely correlated to obesity, eating a more varied diet is usually associated with higher energy intake. Hence, the main question regarding the association between DDS and obesity still remains, and it will be interesting to be assessed [11].

However, lack of dietary diversity is a major nutritional concern over among deprived people from the low-income countries [12]. Changing from a monotonous diet to one with varied food types has been shown to improve energy and nutrient intakes in the people from developing countries. The demographic and economic transition that many developing countries are undergoing is producing important changes in diet and lifestyle that greatly impact on disease risks [13].

This study was undertaken to determine the association between dietary diversity and obesity of school children 6-9 years of age in urban Iran to determine the association between DDS, obesity and overweight. Dietary diversity was examined by calculating scores for 11 food groups. The scores were calculated taking into consideration the number of times different items that were consumed.

\section{Methodology}

The study Subjects were selected from a middle and low socio-economic families of Tehran city in Iran. Data for this study were obtained from a cross-sectional survey designed to evaluate child obesity and dietary diversity. A formula by Fisher was used to calculate the desired sample size of 2500 6-9 years old Iranian school children (1176 girls and 1324 boys) with a response rate of $96.0 \%$. A stratified cluster sampling method was used to select of Participants. They were recruited using from sixteen primary schools which were randomly selected from Tehran Province. Data collection was carried out using a structured, culturally sensitive questionnaire which was pretested and modified accordingly. The parents of children were interviewed in order to obtain information about the child. Fifteen interviewers were taken to conduct the interviews with the mothers of the children. All interviewers were trained for one to two weeks before starting the interview. They had a Diploma in health sciences or were undergraduate students in nutrition sciences. Ethical Approval for this study was obtained by the Department of Research, Ministry of Education and Training, Government of Iran. It was also approved by the ministry of health and medical education. Informed consent was taken from the Principal of each school and the mother of each child before conducting the study.

Height and weight were determined according to standard anthropometric methods (Marfell-Jones, 2006). Height was measured to the nearest $0.1 \mathrm{~cm}$ in bare feet with participants standing upright against a mounted stadiometer. Weight was measured to the nearest $0.1 \mathrm{~kg}$ with participants lightly dressed using a portable Seca digital platform scale (model 770). Body Mass Index was computed as weight $/ \mathrm{height}^{2}\left(\mathrm{~kg} / \mathrm{m}^{2}\right)$.

The World Health Organization's (WHO) Anthro Plus software which is software for the global application of the WHO reference 2007 for 5-19 years to monitor the growth of school age children and adolescents was used to assess the overweight and obese children. The indicators were calculated by standard deviation (SD) or Z-score for all children.

In the present study, the frequency of consumption for the different food items was recorded i.e., daily, 2-3 times per week, once per week, fortnightly, monthly and occasionally. In addition, a food frequency questionnaire was used. The record period should represent usual diet at community level and should reduce memory bias and avoid respondent fatigue. In the present study, a simple count without weighting food items was used and the scores were calculated as follows in Table 1.

One questionnaire was used for all participants regardless of age and gender. First, a list of all foods consumed by children and eleven main food groups were generated. These foods were then divided into eleven main food groups based on food guide pyramid. Main food groups in the questionnaire and each main food group included food items mostly consumed by families which are listed in Table 2.

The data was analyzed using the SPSS windows software version 17.0. Analysis, Means and standard deviations were computed for all variables. Analysis of variance (ANOVA), post-hoc Bonferroni test and two- tailed Students t-test were used to compare different parameters which were studied. Chisquare test was used to determine independence of attributes within and between groups.

\section{Results}

A significant difference was observed in weight for age status based on Z-scores by gender $(\chi 2=30.428, p=0.000)$.

Almost 5 percent of females and 1.7 percent of males were overweight as indicated by the $\mathrm{z}$ scores. A significant difference was observed in weight for age z-scores by age groups $(\chi 2=20.081, p=0.017)$. Overweight school children were more among those who were 7-7.11 year of age.

Comparison between boys and girls showed that up to the age

Table 1. Scores calculation based on food intake frequencies.

\begin{tabular}{|c|c|}
\hline Number of times consumed & Score assigned \\
\hline Daily & 7 \\
\hline $2-3$ times/week & 3 \\
\hline Once/week & 1 \\
\hline Fortnight & 0.5 \\
\hline Monthly & 0.25 \\
\hline Occasionally & 0 \\
\hline
\end{tabular}

Table 2. Food groups and number of items included in each food group.

\begin{tabular}{|c|c|c|}
\hline Number & Food group & Number of food items \\
\hline 1 & Cereals and rice items & 21 \\
\hline 2 & Pulses and legume items & 15 \\
\hline 3 & Dairy products & 10 \\
\hline 4 & Vegetables & 9 \\
\hline 5 & Fruits & 17 \\
\hline 6 & Nuts & 5 \\
\hline 7 & Non-vegetarian items & 9 \\
\hline 8 & Sweets and sugars & 14 \\
\hline 9 & Mixed dishes and snacks & 7 \\
\hline 10 & Beverages & 7 \\
\hline 11 & Fats and oils & 4 \\
\hline
\end{tabular}


of 8.11 years, girls had slightly lower BMI than the boys. In the oldest age group of 9-9.11 years, there was little difference between boys and girls BMI. However, there were no significant differences between males and females for BMI $(\mathrm{F}=0.030$, $\mathrm{p}=0.993$ ). The prevalence of obesity was $22 \%$ for boys and $17.9 \%$ for girls.

Further, comparison of the children by age group, showed that prevalence of overweight and obesity decreased with increasing age. The mean $\mathrm{Z}$ score for the girls for all ages combined was higher compared to their male. In all four age groups, the mean $\mathrm{Z}$ scores for the girls were positive whereas for the boys, those who were in the age groups of 6-6.11 and 9-9.11 years had negative scores.

The mean $\mathrm{Z}$ score was positive for boys between 7 and 8.11 years of age, suggesting that there may have been some weight gain associated with the prepubertal growth spurt. Among the girls, the mean values were higher for the girls between 6 and 7.11 years of age compared to the older girls. However, well designed longitudinal studies with adequate sample size are required in order to determine whether there are differences between children with respect to the age when the growth spurt occurs and the gains in height and weight during this period. With the distribution of z-scores, it was observed that a small percentage of children were overweight, with the prevalence being higher among girls than boys, the differences being statistically significant $(\chi 2=48.829, \mathrm{p}=0.000)$.

A significant difference was observed in weight for height status $\mathrm{z}$-scores by gender of school children $(\chi 2=11.176, \mathrm{p}=0.004)$.

Mean total diversity scores were $150.2 \pm 51.9$. One-way analysis of variance showed that the mean total diversity score for Iranian school children was significantly high $(\mathrm{F}=7.165$, $\mathrm{P}=0.007$ ). Children had lower variety and/or frequency of mean scores for cereals and pulses as well as vegetables. However, the mean score for fruits, dairy products, nuts and especially non-vegetarian food items was high. Non-vegetarian foods were part of the daily meal, and for many children, these foods were part of lunch and/or dinner. However, the score was not very high, because these food items are expensive. Scores for beverages and sweets were high. Fats included edible plant oils, butter, mayonnaise and olive oil used for salads, consumed by children were economically better off families.

According to Table 3 mean \pm SD for food group scores based on children's gender, girls had a better diversity in their diet but in comparison with boys these differences were not statistically significant $(\mathrm{P}=0.101)$. Both genders had low scores for cereal consumption but the mean scores for vegetables, fruit and mixed dishes and fats didn't differ significantly between male and female children. Mean scores for non - vegetarian foods among girls was slightly higher than the scores for boys. Mean scores for mixed dishes were slightly higher in female children than that of boys.

The mean scores were compared by age group for children. Mean scores for cereal consumption increased with increasing age up to 8.11 years but then decreased for the oldest age group. For pulses there was not much difference between the age groups. Similarly mean scores for mixed dishes did not differ significantly by age. Mean scores for non- vegetarian foods was highest among the 8 to 8.11 years old children (Table 4). For vegetables and fruits, mean scores were highest in the oldest age group. Mean scores for dairy foods and nuts consumption was highest among the 7 to 7.11 years age group. There was no significant difference between age groups for beverage consumption. For sweets, the highest mean score was for the 8 and 9 years old children. Fat consumption was highest in the 7 to 7.11 and 8 to 8.11 years old children. Further, significant differences were observed in the total mean scores between age groups. The highest score was observed for the 8-8.11 age group followed by the 9 to 9.11 years old children. The two younger age groups had lower scores and did not significantly differ from each other.

Dietary diversity scores were examined in relation to weight status of the children (Table 5). Total dietary diversity scores were significantly higher for those children who had normal weight or who were overweight $(\mathrm{F}=9.345, \mathrm{p}=0.000)$. Scores were highest among overweight children. Total food group scores increased with better height status of the children $(\mathrm{F}=5.825, \mathrm{p}=0.001)$.

These data suggest that greater diversity is associated with overweight and obesity. Hence, individual food group diversity scores were analyzed in order to determine which food groups

Table 3. Mean $\pm S D$, CI food groups for food group scores based on children's gender

\begin{tabular}{|l|c|c|c|c|c|}
\hline \multirow{2}{*}{ Food Groups } & \multicolumn{2}{|c|}{$\begin{array}{c}\text { Child's Gender } \\
\text { Mean } \pm \text { SD }\end{array}$} & \multicolumn{2}{c|}{$95 \%$ CI } & \multirow{2}{*}{ P value } \\
\cline { 2 - 5 } & Males & Females & Lower & Upper & \\
\hline $\begin{array}{l}\text { Cereals and rice } \\
\text { items }\end{array}$ & $17.0 \pm 8.0$ & $17.8 \pm 7.5$ & 17.1 & 17.8 & 0.006 \\
\hline $\begin{array}{l}\text { Pulses and legume } \\
\text { items }\end{array}$ & $4.0 \pm 4.4$ & $4.3 \pm 4.1$ & 4 & 4.3 & 0.001 \\
\hline Dairy products & $15.8 \pm 6.8$ & $17.1 \pm 8.4$ & 16.1 & 16.9 & 0 \\
\hline Vegetables & $24.3 \pm 16.0$ & $24.7 \pm 15.3$ & 23.9 & 25.2 & 0.187 \\
\hline Fruits & $21.7 \pm 15.5$ & $20.4 \pm 14.2$ & 19.9 & 21 & 0.075 \\
\hline Nuts & $4.2 \pm 5.4$ & $4.4 \pm 5.0$ & 4.1 & 4.5 & 0.021 \\
\hline Non-vegetarian items & $8.8 \pm 4.7$ & $9.1 \pm 4.2$ & 8.8 & 9.1 & 0 \\
\hline Sweets and sugars & $19.0 \pm 11.2$ & $20.0 \pm 10.5$ & 19.1 & 20 & 0.014 \\
\hline $\begin{array}{l}\text { Mixed dishes and } \\
\text { snacks }\end{array}$ & $12.6 \pm 7.0$ & $13.3 \pm 7.5$ & 12.7 & 13.3 & 0.416 \\
\hline Beverages & $11.2 \pm 6.5$ & $11.6 \pm 6.0$ & 11.2 & 11.7 & 0.036 \\
\hline Fats and oils & $9.8 \pm 4.1$ & $10.2 \pm 4.4$ & 9.8 & 10.1 & 0.171 \\
\hline Total scores & $148.3 \pm 50.9$ & $151.9 \pm 52.7$ & 148 & 150.4 & 0.101 \\
\hline
\end{tabular}

Table 4. Mean $\pm S D$ for food group scores based on children's age categories.

\begin{tabular}{|l|c|c|c|c|c|}
\hline \multirow{2}{*}{ Food groups } & \multicolumn{4}{|c|}{ Age groups } & \multirow{2}{*}{ P. Value } \\
\cline { 2 - 6 } & $\mathbf{6 - 6 . 1 1}$ & $\mathbf{7 - 7 . 1 1}$ & $\mathbf{8 - 8 . 1 1}$ & $\mathbf{9 - 9 . 1 1}$ & \\
\hline Cereals and rice & $16.3 \pm 6.5$ & $17.9 \pm 6.0$ & $18.5 \pm 8.9$ & $17.0 \pm 9.1$ & 0 \\
\hline $\begin{array}{l}\text { Pulses and } \\
\text { legume }\end{array}$ & $4.3 \pm 4.2$ & $4.1 \pm 3.0$ & $4.1 \pm 4.8$ & $4.1 \pm 4.6$ & 0.606 \\
\hline Dairy products & $18.5 \pm 9.2$ & $17.7 \pm 7.4$ & $16.4 \pm 8.4$ & $16.0 \pm 9.2$ & 0.002 \\
\hline Vegetables & $24.7 \pm 14.7$ & $23.4 \pm 14.2$ & $24.6 \pm 16.1$ & $25.4 \pm 17.3$ & 0.208 \\
\hline Fruits & $20.2 \pm 15.2$ & $17.0 \pm 11.3$ & $22.1 \pm 14.6$ & $22.6 \pm 15.3$ & 0 \\
\hline Nuts & $4.1 \pm 5.5$ & $4.1 \pm 4.2$ & $4.9 \pm 5.2$ & $4.0 \pm 5.5$ & 0.016 \\
\hline Non-vegetarian & $8.7 \pm 4.9$ & $9.3 \pm 4.1$ & $9.4 \pm 4.3$ & $8.3 \pm 4.4$ & 0 \\
\hline Sweets and & $19.3 \pm 11.4$ & $18.8 \pm 9.4$ & $20.6 \pm 10.2$ & $19.5 \pm 12.2$ & 0.045 \\
\hline sugars & $12.5 \pm 7.2$ & $12.5 \pm 6.1$ & $14.0 \pm 8.0$ & $13.0 \pm 7.9$ & 0.002 \\
\hline Mixed dishes & $11.6 \pm 6.6$ & $11.0 \pm 5.3$ & $11.8 \pm 6.5$ & $11.2 \pm 6.5$ & 0.108 \\
\hline Beverages & $9.6 \pm 4.0$ & $10.5 \pm 4.3$ & $10.4 \pm 4.5$ & $9.2 \pm 4.2$ & 0 \\
\hline Fats and oils & $147.4 \pm 55.9$ & $146.4 \pm 44.7$ & $156.9 \pm 51.2$ & $150.4 \pm 54.8$ & 0.003 \\
\hline Total scores & & & &
\end{tabular}

J Nutr Hum Health 2018 Volume 2 Issue 1 
Table 5. Total food group scores based on weight and body mass index $B M I$

\begin{tabular}{|c|c|c|}
\hline Weight/Age & Mean \pm SD & Weight/Height Mean \pm SD \\
\hline$<-3 S D$ & $123.8 \pm 40.0$ & $0.0 \pm 0.0$ \\
\hline -3SD to $-2 S D$ & $129.4 \pm 53.5$ & $125.2 \pm 39.5$ \\
\hline -2SD to $+2 S D$ & $149.6 \pm 51.8$ & $149.6 \pm 51.9$ \\
\hline$>+2 S D$ & $178.1 \pm 45.9$ & $177.5 \pm 48.7$ \\
\hline (Total) F, P. value & $F=9.345, P=0.000$ & $F=16.038, P=0.000$ \\
\hline
\end{tabular}

Table 6. Mean diversity scores for individual food groups in relation to weight for age $z$ scores categories.

\begin{tabular}{|l|c|c|c|c|}
\hline \multirow{2}{*}{\multicolumn{1}{|c|}{ Food groups }} & \multicolumn{4}{|c|}{ Weight for Age } \\
\cline { 2 - 5 } & $\begin{array}{c}\text { < -3SD X } \\
\mathbf{\pm S D}\end{array}$ & $\begin{array}{c}\mathbf{- 3 S D} \text { to } \\
\mathbf{- 2 S D X} \mathbf{\text { SD }}\end{array}$ & $\begin{array}{c}\mathbf{- 2 S D} \text { to } \\
\mathbf{+ 2 S D X} \pm \mathbf{S D}\end{array}$ & $\begin{array}{c}\mathbf{>}+\mathbf{+ 2 S D X} \\
\mathbf{\pm} \text { SD }\end{array}$ \\
\hline Cereals & $18.1 \pm 0.0$ & $15.5 \pm 6.1$ & $17.4 \pm 7.8$ & $19.5 \pm 6.4$ \\
\hline Pulse\& Legumes & $4.4 \pm 2.3$ & $4.9 \pm 6.7$ & $4.1 \pm 4.2$ & $4.7 \pm 3.2$ \\
\hline Vegetables & $19.1 \pm 0.9$ & $22.1 \pm 11.1$ & $24.3 \pm 15.7$ & $31.3 \pm 12.7$ \\
\hline Fruits & $17.1 \pm 11.5$ & $16.1 \pm 13.1$ & $20.4 \pm 14.4$ & $23.6 \pm 13.5$ \\
\hline Dairy products & $18.5 \pm 2.7$ & $17.7 \pm 13.5$ & $16.4 \pm 8.6$ & $17.0 \pm 5.5$ \\
\hline Non-veg items & $7.7 \pm 3.4$ & $8.2 \pm 5.3$ & $8.8 \pm 4.4$ & $12.0 \pm 4.6$ \\
\hline Nuts & $6.6 \pm 7.7$ & $2.9 \pm 5.3$ & $4.3 \pm 5.2$ & $4.3 \pm 4.0$ \\
\hline Mixed dishes & $14.2 \pm 9.3$ & $9.0 \pm 5.8$ & $12.9 \pm 7.2$ & $16.9 \pm 8.1$ \\
\hline Beverages & $4.0 \pm 2.7$ & $10.6 \pm 6.3$ & $11.3 \pm 6.3$ & $14.7 \pm 4.0$ \\
\hline Sweets & $8.1 \pm 0.8$ & $15.6 \pm 10.4$ & $19.5 \pm 10.9$ & $22.6 \pm 8.9$ \\
\hline Fats & $5.8 \pm 1.1$ & $6.6 \pm 2.4$ & $10.0 \pm 4.2$ & $11.4 \pm 3.5$ \\
\hline
\end{tabular}

Table 7. Mean diversity scores for individual food groups in relation to weight for height $z$ scores categories.

\begin{tabular}{|l|c|c|c|c|}
\hline \multirow{2}{*}{ Food groups } & \multicolumn{4}{|c|}{ Weight for Height } \\
\cline { 2 - 5 } & $<-3 S D$ & $-3 S D$ to -2SD & -2SD to +2SD & $>$ +2SD \\
\hline Cereals & $0.0 \pm 0.0$ & $13.8 \pm 4.0$ & $17.4 \pm 7.8$ & $20.0 \pm 6.8$ \\
\hline Pulse \& Legumes & $0.0 \pm 0.0$ & $4.2 \pm 3.3$ & $4.1 \pm 4.2$ & $4.4 \pm 3.6$ \\
\hline Vegetables & $0.0 \pm 0.0$ & $18.4 \pm 9.1$ & $24.3 \pm 15.6$ & $33.3 \pm 14.1$ \\
\hline Fruits & $0.0 \pm 0.0$ & $14.3 \pm 8.5$ & $20.4 \pm 14.4$ & $23.9 \pm 13.1$ \\
\hline Dairy products & $0.0 \pm 0.0$ & $15.1 \pm 10.2$ & $16.5 \pm 8.7$ & $16.7 \pm 5.6$ \\
\hline Non-veg items & $0.0 \pm 0.0$ & $7.4 \pm 3.1$ & $8.9 \pm 4.4$ & $11.5 \pm 4.6$ \\
\hline Nuts & $0.0 \pm 0.0$ & $4.3 \pm 3.6$ & $4.3 \pm 5.2$ & $4.1 \pm 4.0$ \\
\hline Mixed dishes & $0.0 \pm 0.0$ & $11.9 \pm 6.5$ & $12.8 \pm 7.2$ & $17.3 \pm 8.3$ \\
\hline Beverages & $0.0 \pm 0.0$ & $9.8 \pm 6.7$ & $11.4 \pm 6.3$ & $13.5 \pm 4.8$ \\
\hline Sweets & $0.0 \pm 0.0$ & $18.6 \pm 12.4$ & $19.5 \pm 10.8$ & $20.6 \pm 10.3$ \\
\hline Fats & $0.0 \pm 0.0$ & $8.1 \pm 3.1$ & $9.9 \pm 4.2$ & $12.1 \pm 5.5$ \\
\hline
\end{tabular}

may put the child at risk of overweight and/or obesity. Tables 6 and 7 present the scores for individual food groups in relation to weight for age z-scores and weight for height z-scores, respectively.

The highest mean score for cereals was observed for overweight children and lower scores were observed among moderately underweight children, although these differences were not statistically significant $(\mathrm{F}=2.405, \mathrm{p}=0.065)$. There was no significant difference in mean scores among different weight for age categories for pulses $(\mathrm{F}=0.824, \mathrm{p}=0.480)$, fruits $((\mathrm{F}=2.209$, $\mathrm{p}=0.085)$, dairy products $(\mathrm{F}=0.368, \mathrm{p}=0.776)$ and nuts $(\mathrm{F}=1.039$, $\mathrm{p}=0.374)$. Significant differences were observed between weight categories in the mean scores for vegetables $(F=5.234, p=0.001)$, non-vegetarian food items $(\mathrm{F}=12.392, \mathrm{p}=0.000)$, mixed dishes $(\mathrm{F}=9.899, \mathrm{p}=0.000)$, beverages $(\mathrm{F}=9.654, \mathrm{p}=0.000)$, sweet and sugars $(\mathrm{F}=5.122, \mathrm{p}=0.002)$ and fats $(\mathrm{F}=10.263, \mathrm{p}=0.000)$. Mean scores for vegetables, beverages, sweets and fats consumption increased with increasing weight.

The highest scores observed among overweight children and the lowest score observed among moderately underweight children.
The mean scores for vegetable consumption among the overweight and normal weight children differed significantly from those who were underweight. Similarly, scores for nonvegetarian items, mixed dishes and fats differed significantly among the overweight children. For beverages and sweets mean scores for all weight for age categories differed significantly from each other

Mean scores for cereals, fruits, vegetables, dairy products, mixed dishes, beverages, sweet and fats consumption increased by increasing body mass index (BMI). Also, high scores for pulses and legumes consumption was observed in obese children. Same trends were observed for nuts. Higher mean scores for nut consumption observed among normal height children. Scores for vegetable consumption were higher among overweight children.

\section{Discussion}

Increasing globalization and urbanization along with change in trade policies have given impetus to food industries and increased availability of ready to eat processed foods with longer shelf life that are easily available, all year round, through various outlets. In many countries, diets have become more westernized and intake of processed foods including sugar, sweets, soft drinks and meats have increased. All these influence health and weight of the individual.

Studies in different countries have shown that in general, children's eating patterns have changed over the years with the trends being eating more food away from home, consuming more snacks, drinking more sugar - sweetened beverages along with a decline in breakfast consumption and less consumption of fruits. Ruel and Seo have stated that dietary diversity is associated with child weight [14-17].

McCrory et al. found that dietary diversity within sweets, snacks, condiments and carbohydrate food was positively associated and dietary diversity within the vegetable food group was negatively with energy intake and body fatness [18]. Also, it was demonstrated that low BMI was associated with higher dietary diversity in females but not in males. Kennedy et al. indicated that increased food variety with more fruit and vegetable consumption in most groups was associated with lower energy consumption and thus a lower BMI and perhaps also reduces the risk of obesity [19]. Torheim et al. reported a positive correlation between energy intake and DDS, as well as variety of different food groups in Mali [20]. Animal and human studies showed that food intake increases when there is more variety in a meal or diet and that greater dietary variety is associated with increased body weight and subsequently obesity [21]. Several studies showed a positive correlation between calorie intake and dietary diversity [22]. On the contrary, an inverse association between DDS and obesity/abdominal adiposity was reported among the female students of Isfahan University [23]. In US women, low BMI was associated with higher DDS; in US men, there was no clear relation of BMI to dietary diversity [24].

In contrast, in the present study it was observed that diversity scores were higher for those children who were overweight. Also, when information for individual vegetables was examined, it was observed that the commonly consumed vegetables by 
children were spinach, cucumber, cabbage, tomatoes, celery, parsley, capsicum and potato. The children also consumed vegetable salads. The most commonly consumed fruits were orange, grapes and apple.

These differences may be attributed to diversity scores were calculated in the present study based on the number of items consumed within a food group and the frequency of consumption. However, portion size was not considered. It is possible that children who were overweight tended to consume more amounts of vegetables like potato, yam, etc. and that the method of preparation involved may have used more amount of oil or fat. Further, different investigators have used varied methodologies. Some investigators have assessed dietary diversity based on 24-hour diet recalls; some have taken into account portion sizes whereas many have used food frequencies. In line with the present findings, Azadbakht et al., demonstrated that among Iranian females 18-28 years of age, there was a direct association between energy intake and dietary diversity [8]. Increased energy intake was related to increasing intake of fruit, vegetables and whole grain. This study also showed that there were inverse associations among dietary diversity score, obesity and abdominal adiposity.

Hatloy et al. found that intake of junk food (French fries, burger, chocolate/candy, cake and canned fruits in heavy syrup) was inversely related with BMI of 242 over weight Canadian children 10-19 years old [25]. Moore et al. examined longitudinal changes in consumption of 6 types of beverages (milk, diet and regular soda, fruit juice, fruit flavored drinks and coffee or tea) in girls. Findings showed that consumption of all beverages was associated with calorie intake and increased BMI. Similar observations were made in the present study with reference to beverages, fats and sweets [26].

\section{Conclusion}

Children who were in the overweight category had significantly higher diversity scores for these three food groups compared to children who were wasted or had normal weight for height z scores. The association between dietary diversity and child nutritional status needs to be studied in depth and used for nutrition education to prevent child overweight and obesity. A reduction in dietary variety of highly palatable and energy rich foods may be the best tools to prevent and treat obesity. In the same time, children must encourage to consume high nutrient but low calories food items (e.g. green vegetables, low fat milk) instead of calorie dense foods.

\section{References}

1. Centers for Disease Control and Prevention (CDC) Assessment of body mass index screening of elementary school children. MMWR Morb Mortal Wkly Rep. 2009;58(17):460-3.

2. Johnson A, Ziolkowski GA. School-based body mass index screening program. Nutr Today. 2006;41(6):274-9.

3. Pulgarón ER. Childhood obesity: A review of increased risk for physical and psychological comorbidities. Clin Ther. 2013;35(1):A18-A32.

4. Ogden CL, Flegal KM, Carroll MD, et al. Prevalence and trends in overweight among US children and adolescents, 1999-2000. JAMA. 2002;288(14):1728-32.

5. Kelishadi R, Ardalan G, Gheiratmand R, et al. Caspian Study Group: Thinness, overweight and obesity in a national sample of Iranian children and adolescents: A Caspian Study. Child Care Health Dev. 2008;34(1):44-54.

6. Florentino RF. The burden of obesity in Asia: Challenges in assessment, prevention and management. Asia Pac J Clin Nutr. 2012;11:S676-80.

7. John H, Yohannes Y. Dietary diversity as a food security indicator: Food and Nutrition Technical Assistance Project. 2002; Academy for Educational Development, Washington DC, USA.

8. Azadbakht L, Esmaillzadeh A. Dietary diversity score is related to obesity and abdominal adiposity among Iranian female youth. Public Health Nutr. 2011;14:62-69.

9. Arimond M, Ruel M. Progress in developing an infant and child feeding index: An Example from the Ethiopia Demographic and Health Survey 2000. Food Consumption and Nutrition Division Discussion Paper. International Food Policy Research Institute, Washington, DC, USA. 2002.

10. Daniels MC, Adair LS, Popkin BM, et al. Dietary diversity scores can be improved through the use of food group cutoffs: An analysis in young Filipino children. EJCN. 2007.

11. Azadbakht L, Mirmiran P, Azizi F. Dietary diversity score is favorably associated with the metabolic syndrome in Tehranian adults. Int J Obes (Lond). 2005;29:1361-7.

12. Ruel MT. Operationalizing dietary diversity: A review of measurement issues and research priorities. J Nutr. 2003; 133: 3911S-6S.

13. Popkin B. Nutrition in transition: The changing global nutrition challenge. Asia Pac J Clin Nutr. 2001;10:13-18.

14. Paeratakul S, Ferdinand DP, Champagne CM, et al. Fastfood consumption among US adults and children: dietary and nutrient intake profile. J Am Diet Assoc. 2003;103:1332-8.

15. Jahns L, Siega-Riz AM, Popkin BM. The increasing prevalence of snacking among US children from 1977 to 1996. J Pediatr. 2001;138:493-8.

16. Ruel MT. Operationalizing dietary diversity: A review of measurement issues and research priorities. J Nutr. 2003; 133:3911S-26S.

17. Seo HS, Lee SK, Nam S. Factors influencing fast food consumption behaviors of middle-school students in Seoul: An application of theory of planned behaviors. Nutr Res Pract: 2011;5:169-78.

18. McCrory MA, Fuss PJ, McCallum JE, et al. Dietary variety within food groups: association with energy intake and body fatness in men and women. Am J Clin Nutr. 1999;69:440-47. 
19. Kennedy E, Powell R. Changing eating patterns of American children: A view from 1996. J Am Coll Nutr. 2004;16:524-29.

20. Torheim LE, Ouattara F, Diarra MM, et al. Nutrient adequacy and dietary diversity in rural Mali: association and determinants. Eur J Clin Nutr. 2004;58:594-604.

21. Raynor HA, Epstein LH. Dietary variety, energy regulation, and obesity. Psychol Bull. 2001;127:325-41.

22. Mirmiran P, Azadbakht L, Azizi F. Dietary diversity within food groups: an indicator of specific nutrient adequacy in Tehranian women. J Am Coll Nutr. 2006;25:354-61.

23. Drescher LS, Thiele S, Mensink GB. A new index to measure healthy food diversity better reflects a healthy diet than traditional measures. J Nutr. 2007;137:647-51.
24. Kant AK, Schatzkin A, Harris TB, et al. Dietary diversity and subsequent mortality in the first national health and nutrition examination survey epidemiologic follow-up study. Am J Clin Nutr. 2003;57:434-40.

25. Hatløy A, Hallund J, Diarra MM, et al. Food variety, socioeconomic status and nutritional status in urban and rural areas in Koutiala (Mali). Public Health Nutr. 2000;3:57-65.

26. Moore S, Thompson D, Affenito SG, et al. Correlates of beverage intake in adolescent girls: The National Heart, Lung, and Blood Institute Growth and Health Study. J Pediatr. 2006;148(2):183-7.

\section{*Correspondence to:}

Sahar Hooshmand

Den Haag

The Hauge

The Netherlands

Tel: +0031616554295

E-mail: sahar.hooshmand40@gmail.com 